\title{
EFFECT OF ELECTRIC PARAMETERS OF ARC SURFACING USING FLUX-CORED WIRE ON PROCESS STABILITY AND BASE METAL PENETRATION
}

\author{
Yu.N. LANKIN, I.A. RYABTSEV, V.G. SOLOVIOV, Ya.P. CHERNYAK and V.A. ZHDANOV \\ E.O. Paton Electric Welding Institute, NASU
}

11 Bozhenko Str., 03680, Kiev, Ukraine. E-mail: office@paton.kiev.ua

\begin{abstract}
Effect of electric parameters of arc surfacing using self-shielding flux-cored wires on process stability and base metal penetration was investigated. The experiments were carried out with computer registration of electric parameters of surfacing. The results of oscillogram processing were used for plotting of $I_{\mathrm{w}}$ and $U_{\mathrm{w}}$ diagrams with outlined areas of stable process of surfacing, short circuits and arc extinctions. Coefficient of process instability $\gamma$ was derived from received real parameters of arc surfacing using flux-cored wire. It is determined that voltage has the largest effect on stability indices and its rise improves process stability. Effect of modes of surfacing on penetration and portion of base metal in the deposited metal was investigated. 3D chart was plotted on estimation results. An area of optimum modes, providing sufficient stability of the process at minimum penetration and good formation of deposited beads, is outlined. 4 Ref., 2 Tables, 7 Figures.
\end{abstract}

Key words: arc surfacing, flux-cored wire, stability of surfacing process, instability coefficient, base metal penetration, portion of base metal

Necessary composition of the deposited metal in multilayer arc surfacing can be obtained only in the third or fourth layer [1] due to its mixing with the base metal. Five layers as minimum should be surfaced, if machining of part is necessary after surfacing. The problem becomes more complicated due to the fact that rise of thickness of the deposited layer promotes for growth of residual shearing stresses and, simultaneously, increases the possibility of appearance in the deposited layer of different type defects, which reduce its service properties, including fatigue life under cyclic loading [2, 3]. Thus, one of the most important characteristics for surfacing is a portion of base metal (PBM) in the deposited metal proportional to base metal penetration other things equal. Reduction of the base metal penetration not only decreases consumption of expensive consumables, but improves quality and service properties of the parts to be surfaced.

Aim of the present work is a study of effect of electric parameters of flux-cored arc surfacing, in particular, stability of these indices on characteristics of the base metal penetration.

Consumables and equipment. Self-shielding flux-cored wire PP-AN130 was used for investigations. It provides for production of surfaced metal of tool steel 25Kh5FMS type. Gas-slag- forming system of the flux-cored wire, which would provide the best welding-technological properties, was preliminary selected. Four selfshielding flux-cored wires PP-AN130 of $2 \mathrm{~mm}$ diameter having different systems of gas-slagforming components, namely $\mathrm{CaO}+\mathrm{TiO}_{2}+$ $\mathrm{MgO}+\mathrm{CaF}_{2}+\mathrm{Al}_{2} \mathrm{O}_{3}$ (wire with reference designation PP-AN130-1); $\mathrm{CaO}+\mathrm{MgO}+\mathrm{CaF}_{2}+$ $\mathrm{Al}_{2} \mathrm{O}_{3}$ (PP-AN130-2); $\mathrm{CaO}+\mathrm{CaF}_{2}+\mathrm{Al}_{2} \mathrm{O}_{3}$ (PP$\mathrm{AN} 130-3) ; \mathrm{CaO}+\mathrm{CaF}_{2}+\mathrm{Al}_{2} \mathrm{O}_{3}+$ starch (PPAN130-4), were manufactured for this purpose.

Expert estimation (5 examiners) of the welding-technological properties of all four wire types (nature of metal transfer, slag coating of the deposited beads, presence of pores) was carried out. The following system of the expert estimations was used for that. The transfer was marked by the following digits, namely 1 - fine-drop; 2 - globular; 3 - mixed; level of slag coating was estimated in percents; porosity - using twopoint system: pores are present (yes) or absent (no). The preference was given to fine-drop transfer, $100 \%$ slag coating of the deposited beads and absence of pores in the deposited metal.

Surfacing of the specimens was carried out using 230-250 A current and $20 \mathrm{~m} / \mathrm{h}$ rate. Voltage has the key effect on pore formation in fluxcored wire surfacing [4], therefore it was varied from $24 \mathrm{~V}$ and higher up to pore formation in the deposited metal for each type of flux-cored wire (Table 1). 

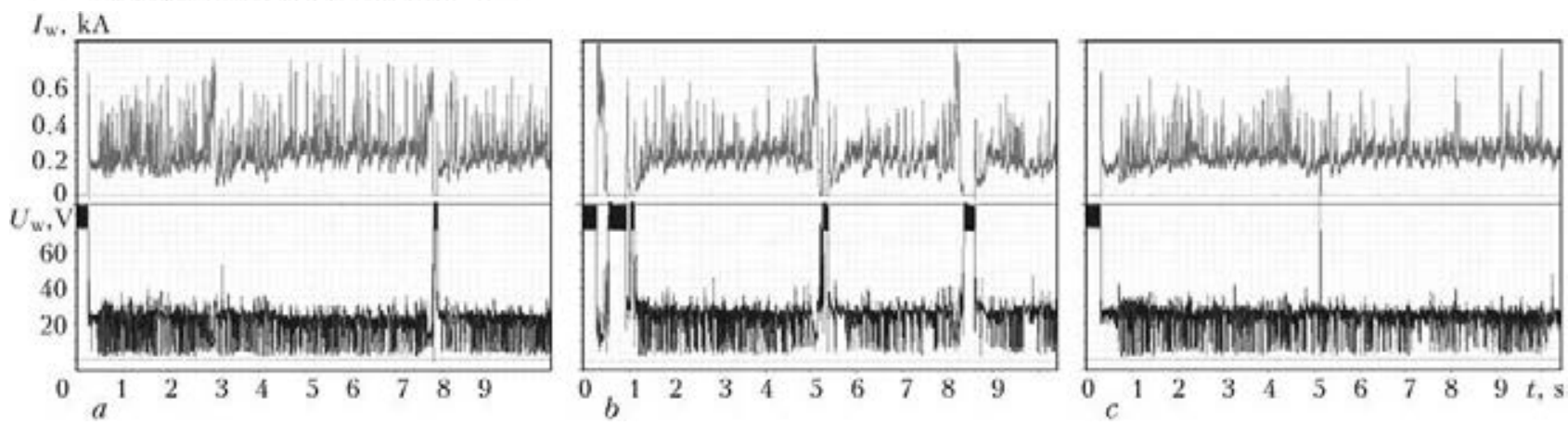

Figure 1. Oscillograms of current and voltage in surfacing using PP-AN130-1 flux-cored wire at different modes: $a-c-$ experiments 2, 5 and 8, respectively, according to Table 2

According to expert estimation flux-cored wire PP-AN130-1 has the best welding-technological properties and it was selected for further experiments.

AD-231 automatic surfacing machine with VDU 506 rectifier was used for surfacing experiments. Surfacing was made on sheets from steel St.3 of $15 \mathrm{~mm}$ thickness. Surfacing current and voltage were registered with the help of computer data measurement system. Instrument shunt 75ShS-450-05 was used as a primary measuring welding current converter, and resistor devider 10:1 was applied for voltage determination. Measuring voltage converter L-Card E14-440 with imbedded 14-row 16-channel AD converter having conversion frequency up to $440 \mathrm{kHz}$ was used for digitization and enter of data of primary converters in the computer. Registration of the parameters in our experiments was performed at $20 \mathrm{kHz}$ frequency, which is sufficient enough for accurate study of high-rate processes in the arc,

Table 1. Results of estimation of welding-technological properties of flux-cored wires of PP-AN130 type

\begin{tabular}{||c|c|c|c|c||}
\hline \multirow{3}{*}{$\begin{array}{c}\text { Designation of } \\
\text { flux-cored wire }\end{array}$} & Voltage, V & $\begin{array}{c}\text { Slag } \\
\text { coating, \% }\end{array}$ & $\begin{array}{c}\text { Presence } \\
\text { of pores }\end{array}$ & $\begin{array}{c}\text { Character } \\
\text { of } \\
\text { transfer, } \\
\text { point }\end{array}$ \\
\hline \multirow{3}{*}{ PP-AN130-1 } & 24 & 100 & No & 3 \\
\cline { 2 - 5 } & 28 & 100 & Same & 3 \\
\cline { 2 - 5 } & 32 & 100 & Yes & 2 \\
\hline \multirow{3}{*}{ PP-AN130-2 } & 24 & 100 & No & 3 \\
\cline { 2 - 5 } & 28 & 80 & Yes & 3 \\
\cline { 2 - 5 } & 32 & 60 & Same & 2 \\
\hline \multirow{3}{*}{ PP-AN130-3 } & 24 & 100 & No & 3 \\
\cline { 2 - 5 } & 28 & 100 & Same & 3 \\
\cline { 2 - 5 } & 32 & 80 & Yes & 2 \\
\hline \multirow{2}{*}{ PP-AN130-4 } & 24 & 90 & No & 1 \\
\cline { 2 - 5 } & 28 & 90 & Same & 3 \\
\cline { 2 - 5 } & 32 & 90 & » & 3 \\
\cline { 2 - 5 } & 34 & 90 & » & 3 \\
\cline { 2 - 5 } & 36 & 90 & Yes & 3 \\
\hline
\end{tabular}

for example, arc gap short-circuiting. Figure 1 and Table 2 provide for current and voltage oscillograms of surfacing at different modes using self-shielding flux-cored wire PP-AN130-1.

Data processing was carried out using specially-designed software in Visual Studio.NET, PowerGraph3.3 and MATLAB 7 media. Current condition of process being studied (arc ignition, arc extinction, short circuiting of arc gap, period of arcing) is automatically identified on data entered in the computer, and parameters of current and voltage for corresponding condition of surfacing process are calculated.

Results. A full-factorial experiment was carried out in order to determine the effect of surfacing current and voltage on process instability and PBM in the deposited metal. Current and voltage (factors) were varied at three levels, that give the possibility to construct a second-order model, providing more adequate description of the process being studied. The currents were set at 200, 250 and 300 A levels, voltage - at 22, 24 and $26 \mathrm{~V}$. Surfacing rate in all cases was constant and made $20 \mathrm{~m} / \mathrm{h}$. Table 2 gives measured and calculated process parameters.

$3 \mathrm{D}$ diagrams of distribution of $U_{\mathrm{w}}$ and $I_{\mathrm{w}}$ joint probability density only for surfacing process without period of initial arc ignition are shown in Figure 2. Probability $p$ of appearance of specific combination of current and voltage in corresponding section of $\left(I_{\mathrm{w}}-U_{\mathrm{w}}\right)$ plane is plotted along the vertical axis. The areas of arcing and short circuiting are outlined on the diagrams. Since arc extinctions in surfacing are rare and their duration is short, the probability density is also very small and being indistinguishable on the diagrams.

Figure 2 and Table 2 show that rise of arc voltage promotes for process stabilizing, i.e. number and duration of short circuits and arc extinctions is reduced. Short circuits and arc extinctions are virtually absent at $26 \mathrm{~V}$ voltage. However, appearance of pores in the deposited metal is shown with rise of voltage and, respectively, 
Table 2. Parameters of process of arc surfacing using self-shielding flux-cored wire PP-AN130-1

\begin{tabular}{|c|c|c|c|c|c|c|c|c|c|}
\hline \multirow{2}{*}{ Parameter } & \multicolumn{9}{|c|}{ Number of experiment } \\
\hline & 1 & 2 & 3 & 4 & 5 & 6 & 7 & 8 & 9 \\
\hline$U_{\mathrm{w}}, \mathrm{V}$ & 22.4 & 21.8 & 20.8 & 23.7 & 24.8 & 23.5 & 25.3 & 24.4 & 26 \\
\hline $\mathrm{V}\left(U_{\mathrm{w}}\right)$ & 0.50 & 0.32 & 0.68 & 0.22 & 0.31 & 0.19 & 0.17 & 0.18 & 0.11 \\
\hline$I_{\mathrm{w}}, \mathrm{A}$ & 188 & 256.7 & 293.7 & 181.9 & 243.5 & 288.1 & 193.5 & 241.2 & 277.9 \\
\hline $\mathrm{V}\left(I_{\mathrm{w}}\right)$ & 0.54 & 0.45 & 0.69 & 0.39 & 0.35 & 0.31 & 0.29 & 0.27 & 0.22 \\
\hline$I_{\mathrm{a}}, \mathrm{A}$ & 174.5 & 239.4 & 235.3 & 175.4 & 241.1 & 280.7 & 190.4 & 237.8 & 277.2 \\
\hline $\mathrm{V}\left(I_{\mathrm{a}}\right)$ & 0.41 & 0.37 & 0.48 & 0.32 & 0.30 & 0.26 & 0.25 & 0.25 & 0.22 \\
\hline$U_{\mathrm{a}}, \mathrm{V}$ & 23.6 & 23.3 & 23.7 & 24.6 & 24.9 & 24.1 & 25.7 & 24.8 & 26.1 \\
\hline $\mathrm{V}\left(U_{\mathrm{a}}\right)$ & 0.17 & 0.15 & 0.21 & 0.12 & 0.15 & 0.12 & 0.11 & 0.13 & 0.10 \\
\hline$I_{\text {sh.c. }}, \mathrm{A}$ & 369.5 & 433.5 & 528.8 & 325 & 493.4 & 485.3 & 328.5 & 385.6 & 435.4 \\
\hline $\mathrm{V}\left(I_{\text {sh.c. }}\right)$ & 0.39 & 0.33 & 0.27 & 0.37 & 0.34 & 0.28 & 0.36 & 0.32 & 0.29 \\
\hline$U_{\text {sh.c }}, \mathrm{V}$ & 6.6 & 6.2 & 9.2 & 4.6 & 7.9 & 6.7 & 5.5 & 6.1 & 7.3 \\
\hline $\mathrm{V}\left(U_{\text {sh.c }}\right)$ & 0.61 & 0.44 & 0.40 & 0.41 & 0.49 & 0.37 & 0.69 & 0.38 & 0.33 \\
\hline$t_{\mathrm{a}}, \%$ & 90.76 & 90.81 & 77.23 & 95.62 & 97.59 & 96.40 & 97.70 & 97.65 & 99.57 \\
\hline$t_{\text {sh.c }}, \%$ & 6.60 & 8.94 & 19.57 & 4.38 & 1 & 3.60 & 2.30 & 2.28 & 0.43 \\
\hline$t_{\mathrm{ex}}, \%$ & 2.60 & 0.25 & 3.20 & 0 & 1.41 & 0 & 0 & 0.07 & 0 \\
\hline$F_{\text {sh.c }}, \mathrm{Hz}$ & 13.29 & 19.25 & 13.75 & 14.58 & 2.49 & 8.21 & 9.91 & 8.38 & 1.99 \\
\hline$T_{\mathrm{ig}}, \mathrm{s}$ & 0 & 0 & 0.45 & 0 & 0.83 & 0 & 0 & 0 & 0 \\
\hline$T_{\mathrm{w}}, \mathrm{s}$ & 42.33 & 41.12 & 43.85 & 39.98 & 41.41 & 41.51 & 40.13 & 39.99 & 42.03 \\
\hline$N_{\text {ex }}$ & 10 & 3 & 21 & 0 & 6 & 0 & 0 & 1 & 0 \\
\hline$N_{\text {sh.c.ig }}$ & 1 & 1 & 5 & 1 & 7 & 1 & 1 & 1 & 1 \\
\hline$\gamma$, rel. un. & 1.03 & 0.607 & 1.78 & 0.47 & 0.59 & 0.41 & 0.38 & 0.39 & 0.32 \\
\hline$g_{0}, \%$ & 34.75 & 24.10 & 20.60 & 39.10 & 30.20 & 330 & 42.35 & 29.10 & 33.10 \\
\hline \multicolumn{10}{|c|}{$\begin{array}{l}\text { Note. } U_{\mathrm{w}}, I_{\mathrm{w}}-\text { average values of voltage and current during surfacing; } \mathrm{V}\left(U_{\mathrm{w}}\right), \mathrm{V}\left(I_{\mathrm{w}}\right)-\text { coefficients of variation of voltage and current } \\
\text { during surfacing, where coefficient of variation is the relationship of root-mean-square value of parameter to its average value; } I_{\mathrm{a}}, U_{\mathrm{a}}, \mathrm{V}\left(I_{\mathrm{a}}\right) \text {, } \\
\mathrm{V}\left(U_{\mathrm{a}}\right)-\text { average values of current, voltage, coefficient of current and voltage variation during arcing (without periods of initial arc excita- } \\
\text { tion); } I_{\text {sh.c }}, U_{\text {sh.c }} \mathrm{V}\left(I_{\text {sh.c }}\right), \mathrm{V}\left(U_{\text {sh.c }}\right)-\text { average values of current, voltage, coefficient of current and voltage variation during arc gap short } \\
\text { circuiting (without periods of initial arc excitation); } t_{\mathrm{a}}-\text { specific duration of arcing, equal total duration of periods of arcing and total } \\
\text { time of welding without period of arc ignition; } t_{\mathrm{sh} . \mathrm{c}}-\text { specific duration of short circuits, equal total duration of periods of short circuits and } \\
\text { total time of welding without arc ignition period; } t_{\mathrm{ex}}-\text { specific duration of arc extinctions, equal relationship of total duration of periods } \\
\text { of arc extinction to total duration of surfacing; } F_{\mathrm{sh.c}}-\text { frequency of arc gap short circuiting without period of arc ignition; } T_{\mathrm{ig}}, T_{\mathrm{w}}-\text { dura- } \\
\text { tion of time of initial arc excitation and total duration of surfacing; } N_{\text {sh.s.ig }}-\text { quantity of short circuits during the period of initial arc exci- } \\
\text { tation; } N_{\mathrm{ex}}-\text { number of extinctions during } T_{\mathrm{w}} ; \gamma-\text { coefficient of process instability; } g_{0}-\text { PBM in deposited metal. }\end{array}$} \\
\hline
\end{tabular}

arc length in self-shielding flux-cored wire surfacing.

Coefficient of instability $\gamma$ was used for estimation of instability of process of flux-cored arc surfacing:

$$
\begin{gathered}
\gamma=\left[\mathrm{V}\left(U_{\mathrm{a}}\right)+\mathrm{V}\left(I_{\mathrm{a}}\right)\right] t_{\mathrm{a}}+ \\
{\left[\mathrm{V}\left(U_{\text {sh.c }}\right)+\mathrm{V}\left(I_{\text {sh.c }}\right)\right] t_{\text {sh.c }}+t_{\text {ex }} N_{\text {ex }} .}
\end{gathered}
$$

It is the sum of coefficients of variation of arcing current and voltage, coefficients of variations of current and voltage of arc gap short circuiting, number of arc extinctions multiplied by weight coefficients. Specific durations of arcing, arc gap short circuiting and arc extinctions were taken as weight coefficients (for designations see Table 2).

Dependence of instability coefficient of surfacing process on current and voltage was received on formula (1) and data from Table 2 in a form of regression second-order model. Figure 3 shows geometric representation of this model (response surface). Lines of constant value of instability coefficient (lines of equi-response) are also shown in $\left(I_{\mathrm{w}}-U_{\mathrm{w}}\right)$ plane. The minimum number of arc extinctions and short circuits is observed at $25 \mathrm{~V}$ voltage. The coefficient of instability $\gamma$ lies in the ranges from 0.50 to 0.32 and arcing is more stable at this current and voltage, changing 

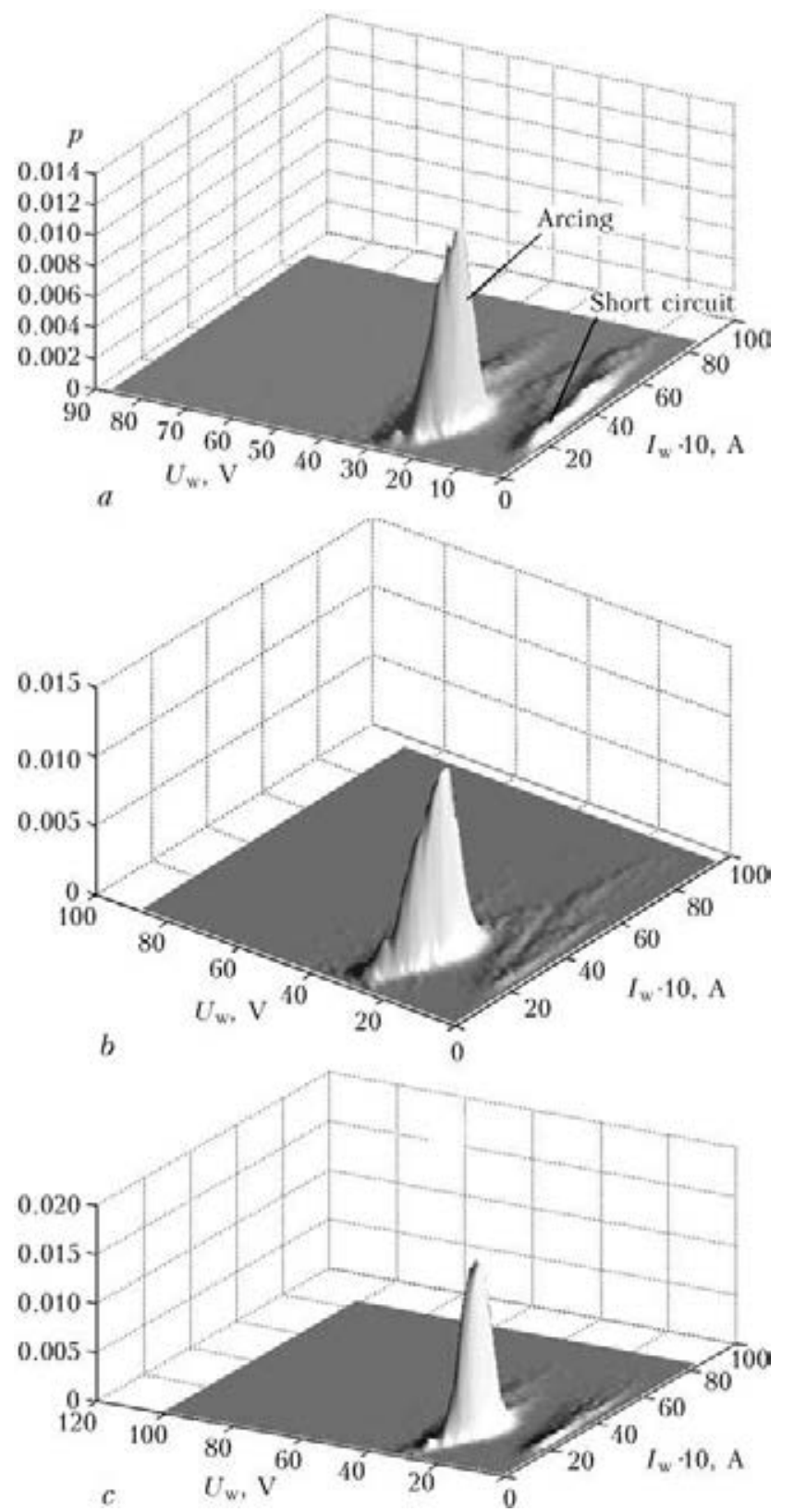

Figure 2. Distribution of joint probability density of surfacing current and arc voltage calculated for oscillograms in Figure 1

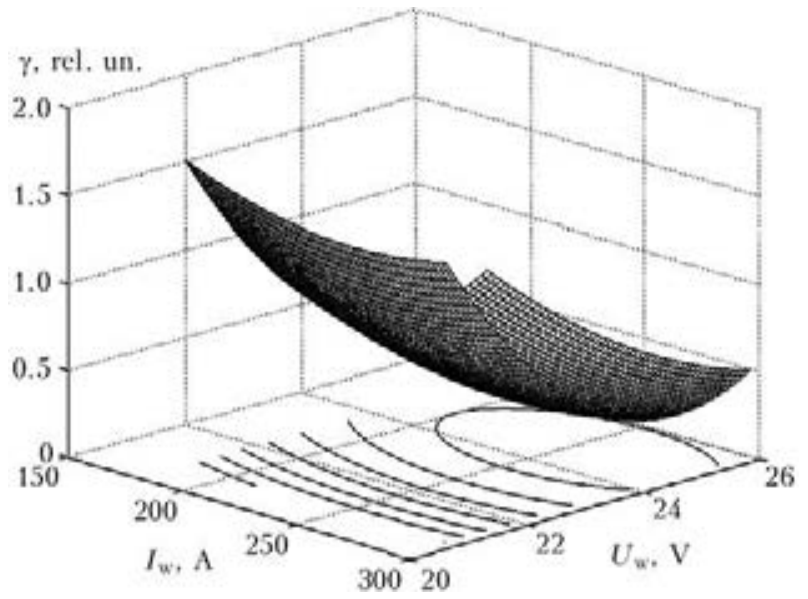

Figure 3. Dependence of coefficient of instability of arc process on surfacing current and arc voltage in surfacing using self-shielding flux-cored wire PP-AN130-1

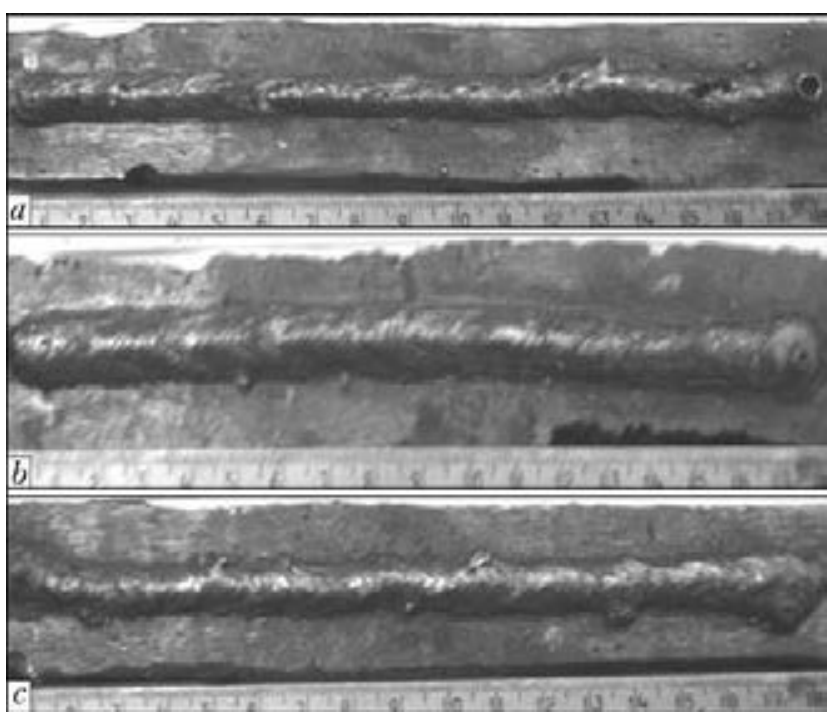

Figure 4. Appearance of beads deposited by flux-cored wire PP-AN130-1 at $200(a), 250(b)$ and $300(c)$ A, $22 \mathrm{~V}$ and $20 \mathrm{~m} / \mathrm{h}$

in the ranges from 200-300 A. The coefficient of instability rises up to $0.9-1.0$ in voltage reduction to $22 \mathrm{~V}$ and at the same currents.

Specimens deposited using the modes given above were also used for investigation of effect of surfacing modes on penetration and PBM in the deposited metal. As an example, Figure 4 shows the appearance of beads, deposited using different currents at $22 \mathrm{~V}$ and $20 \mathrm{~m} / \mathrm{h}$, and $\mathrm{Fi}$ gure 5 represents transverse macrosections of these beads.

Cutting of all specimens across the deposited beads was carried out after surfacing. Eight macrosections were manufactured from each specimen. They were used for determination of average from eight measurements of PMB in the deposited metal $g_{0}$ (see Table 2).

The calculation was carried out on expression

$$
g_{0}=\frac{F_{0}}{F_{0}+F_{\mathrm{d}}} 100 \%,
$$

where $F_{0}$ is the cross-section of molten base metal; $F_{\mathrm{d}}$ is the cross-section of deposited metal.

Regression equitation of $g_{0}$ dependence on current and voltage was received as for instability coefficient. Figure 6 shows respective response

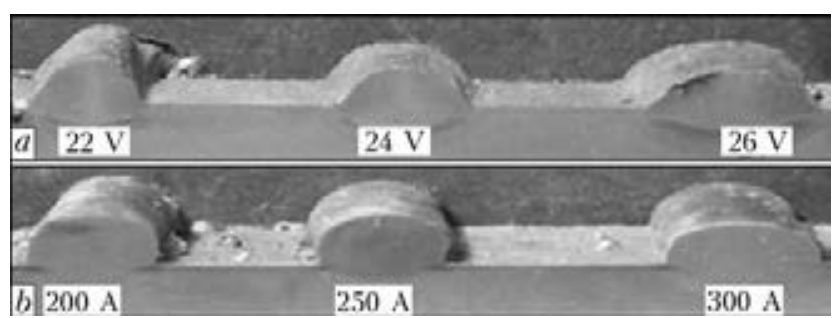

Figure 5. Macrosections of beads deposited using flux-cored wire PP-AN130-1 at different voltages, $250 \mathrm{~A}(a)$, and different currents, $24 \mathrm{~V}(b)$ 


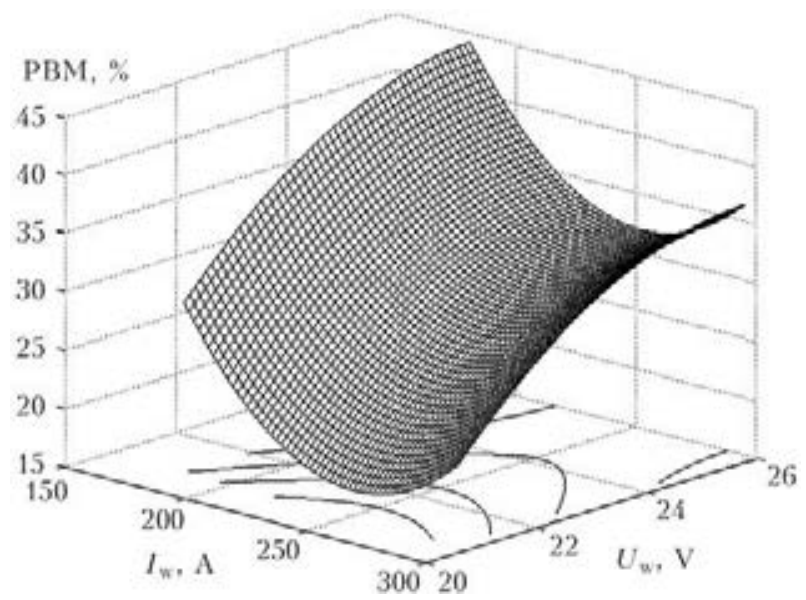

Figure 6. Dependence of PBM in the deposited metal on current and arc voltage

surface. Tendency to PBM decrease is observed in rise of surfacing current. It is related with the fact that the increase of surfacing current is directly connected with the rise of wire feed rate. This increases quantity of the deposited metal per unit of weld length at constant rate of surfacing. Rise of voltage from 22 to $24 \mathrm{~V}$ results in some increase of $g_{0}$ index at all values of surfacing current. However, this index does not change at further increase of voltage up to $26 \mathrm{~V}$.

Relationship between quality of deposited bead formation, PBM in the deposited metal and indices of stability of surfacing process were also estimated. Figure 7 gives the combined 2D sections of the response surface for instability coefficient and PBM in the deposited metal. Area of optimum modes, providing sufficient process stability at minimum penetration and good formation of the deposited beads, is outlined by grey color. This area includes such modes of surfacing of specific part, selecting of which to the utmost fulfill conditions of its operation, structure of part and requirements to the deposited metal. In particular, if structure of the part requires surfacing of layers of large thickness in several passes, then more intensive mode of surfacing with sufficiently large penetration in the first pass can be selected. Surfacing of thin layer requires using the modes from area of surfacing process minimum stability with large bridging of the neighbor beads.

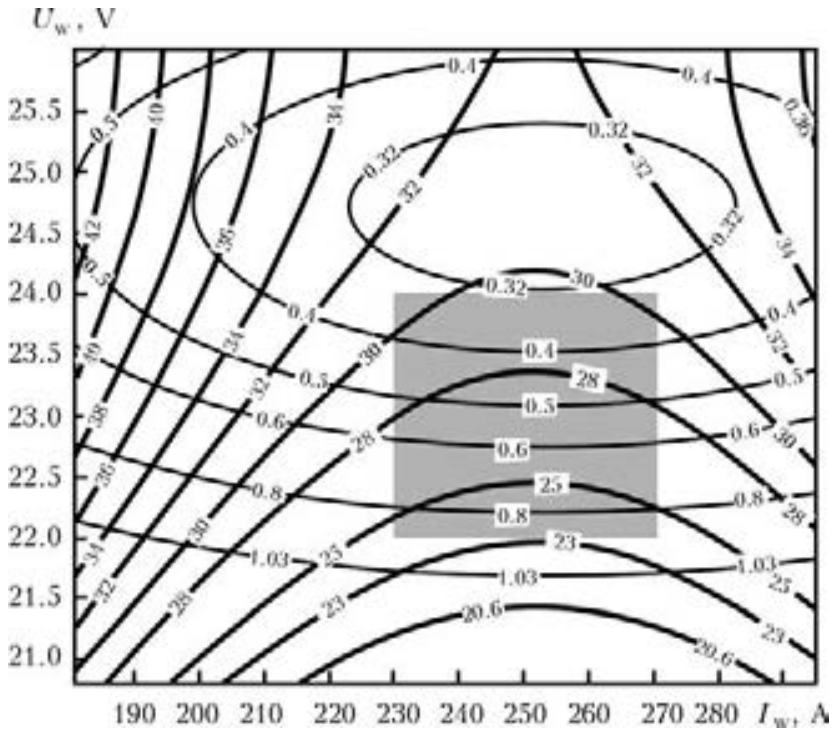

Figure 7. Contour curves of instability coefficient of arcing and PBM in the deposited metal

\section{Conclusions}

1. It is determined that wire having $\mathrm{CaO}+\mathrm{TiO}_{2}+$ $\mathrm{MgO}+\mathrm{CaF}_{2}+\mathrm{Al}_{2} \mathrm{O}_{3}$ gas-slag-forming system has the best welding-technological properties among the experimental self-shielding flux-core wires of PP-AN130-1 type.

2. Instability of arcing depends, first of all, on voltage and reduces with its rise. Coefficient of instability reaches the minimum at $25 \mathrm{~V}$ in the carried experiments with use of self-shielding flux-cored wire of $2 \mathrm{~mm}$ diameter. Current has significantly smaller effect on arcing instability. The minimum instability coefficient for indicated wire is observed at 250-260 A.

3 . Area of optimum surfacing modes, providing sufficient stability of the process $(\gamma=0.32-$ $0.80)$ at satisfactory penetration $\left(g_{0}=23-30 \%\right)$, lies in 230-270 A current and 22-24 V voltage change range.

1. Frumin, I.I. (1961) Automatic electric arc surfacing. Kharkov: Metallurgizdat.

2. Ryabtsev, I.A., Kondratiev, I.A., Babinets, A.A. et al. (2012) Effect of high-temperature thermal cycling on deposited metal of the type of heat-resistant die steels. The Paton Welding J., 2, 22-24.

3. Senchenkov, I.K., Chervinko, O.P., Ryabtsev, I.A. et al. (2013) Determination of service resource of surfaced parts under cyclic, thermal and mechanic loads. Svarochn. Proizvodstvo, 1, 8-3.

4. Yuzvenko, Yu.A., Kirilyuk, G.A. (1973) Surfacing with flux-cored wire. Moscow: Mashinostroenie. 